\title{
Developing a System for Teaching Effectiveness by Student Classification of Teacher Attributes at the University of Lahore College for Women University
}

\section{Hafsah Batool Lahore}

Lecturer of Economics, Department of Economics, Lahore College for Women University Lahore (LCWU) Pakistan batooleconomist@gmail.com

\section{Nabeela Nazly}

Deputy Controller of Examination,Lahore College for Women University Lahore (LCWU) Pakistan nabeela.nazly@lcwu.edu.pk

\begin{abstract}
As teaching effectiveness is crucial for achieving academic excellence, teachers' attributes contributing towards teaching effectiveness are worth exploring. This study examines 300 BS. Education and Economics students' perception of teachers' characteristics who have taught them. Accordingly, teachers are categorized based on scores of attributes obtained through student ratings. Association between teacher attributes and overall teaching effectiveness is found, and finally, a teaching effectiveness framework is designed based on characteristics, which were significantly associated with teaching effectiveness. The majority $(>60 \%)$ of students rated all attributes under the medium category, with $54.64 \%$ and $50.61 \%$ of students placing (rating) overall teaching effectiveness under the high and medium sort respectively, with $17.61 \%$ under the low category. Also, all attributes were found to be positively correlated with overall teaching effectiveness. Out of 30 items under all attributes, 22 items significantly associated with teaching effectiveness were included in the teaching effectiveness framework. In light of the findings, we give teachers suggestions regarding their teaching attributes as perceived by students.
\end{abstract}

Keywords:

Effectiveness; Attributes; Rating

Article Received: 18 October 2020, Revised: 3 November 2020, Accepted: 24 December 2020

\section{INTRODUCTION}

Ensuring high teaching quality in education has been a significant concern to develop graduates with appropriate skills and attitudes to take the fate of the economy in the right direction, and therefore, in the long run, ensuring food security for all (FAO 2014). Keeping a vigil on the teaching quality has been an equal concern for the regulatory bodies on higher education throughout the world, for which several measures have been adopted such as students' feedback, self-appraisal, peer review, microteaching, outcome analysis, 360-degree feedback, performance appraisal by the seniors and administrators, etc. The extant literature on effective teaching and learning styles, tools, or technology, has not considered agricultural education within its sample (Cano et al., 1992). Therefore, understanding agricultural education from this lens becomes important (McKemand Velez, 2015). An insight into the theoretical perspectives of teaching and learning improves teaching quality, hence teaching effectiveness. Creating and maintaining the effectiveness of instruction is essential for the sustainability of agricultural education programs (Roberts and Dyer, 2004).

Teaching effectiveness is a well-researched construct under various contexts (Berk, 2013). However, due to the changing assessment methods, availability of sophisticated statistical tools, accessibility to student information, a better understanding of this concept is demanded (Stronge et al., 2011). Furthering this demand and defining the scope of this study, student ratings of teaching effectiveness will be taken to develop a framework of teaching effectiveness in the context of agricultural education. The validity and utility of student perspective of teaching effectiveness require evidence in various contexts (Galbraith et al., 2012). Also, it is imperative to understand its utility and associated bias. This will help facilitate the implementation of student assessment systems 
effectively (Marsh and Roche, 1997). As a result, looking at the criteria for evaluating the validity of the student assessment of teaching effectiveness, this research would lead to a deeper understanding of the definition of teaching effectiveness and the relevant aspects of student evaluations around it.

\section{LITERATURE REVIEW}

Several decades of research have established the significance of the teaching effectiveness construct in teaching and learning literature. According to Lin, Xie, Jeng, and Huang (2010), teaching effectiveness primarily constitutes two concepts: self-effectiveness and effective teaching. Self-effectiveness refers to the subjective evaluation of the teacher's teaching ability, which influences the student learning outcomes. Effective teaching can be defined as:

the efficient use of knowledge,

the familiarisation of pedagogical resources and technology,

the generation of knowledge over course material, the development of a favorable learning atmosphere, students' encouragement, and the engendering of excellence in student results (Lin et al., 2010).

An effective teacher can also be defined as one who can generate positive learning outcomes in cognitive, behavioral, and affective domains (Anderson, 1979). Though teaching effectiveness can be assessed through several dimensions, those identified as contributing most towards better teaching quality include instructional effectiveness, appropriate student learning assessment, positive classroom environment, and the teacher's traits (Stronge et al., 2011). Teaching effectiveness is considered a complex and intensely personal process, including various variables (Galbraith et al., 2012). Teaching effectiveness provides evidence that is of importance in academics. It includes support for formative decisions (related to improvement in teaching quality) and summative choices (including the overall performance of a teacher and promotion related verdicts) (Berk, 2005). The outcomes of teaching effectiveness might be impactful in short-term and long-term learning processes, which are generally contingent on the overall teaching-learning model practiced in an academic institute (Seidel and Shavelson, 2007).

Student ratings are being widely used for evaluating teaching effectiveness (Chen and Hoshower, 2003). The ratings are captured through a questionnaire, which usually measures teaching behaviors and teaching style (Chen and Hoshower, 2003). Multidimensurality, stability, and reliability, the instructor's function in teaching the course instead of the time, validity over other indicators, not easily affected by potential biases, and a high utility for the teacher, administrators, and researchers are prominent features of student ratings. (Marsh and Bailey, 1993) . Overall, it provides a formative response to a faculty over its teaching pattern, course content, and classroom management (Chen and Hoshower, 2003). Distinct components that reflect the multidimensionality of teaching effectiveness must be included in the student's evaluation proforma. Multidimensionality is useful from the point of view of functional assessment; instead, it helps generate a sophisticated, realistic preview of teaching by any instructor (Marsh and Roche, 1997).

Student ratings have been considered to provide reliable evidence in teaching quality (Marsh and Bailey, 1993). Despite some contradictory findings, the ratings have suggested consistent proof of quality for a particular teacher across courses and time (Murray, 1983). Student ratings to capture teaching effectiveness have also been extensively analyzed in the extant literature (Berk, 2013). Apart from playing a pivotal role in assessing teaching quality and improving teaching, it has also been used for making faculty career advancement/personnel decisions as discussed earlier (Galbraith et al., 2012; Marsh and Roche, 1993; Rockoff and Speroni, 2010). Literature has even documented the outcomes of student ratings of teaching effectiveness in terms of student motivation, learning, study strategy, and course selection (Chen and Hoshower, 2003; 
Marsh and Roche, 1993; Marsh and Roche, 1997). The outcome in terms of improved teaching quality holds tremendous significance for various academic settings (Marsh and Roche, 1993).

Student ratings are dominant, but other indicators have also gained both practitioners and researchers (Rockoff and Speroni, 2010). The other sources include peers, self-rating, videos, alumni, administrators, student interviews, teaching scholarships, awards, learning outcomes, and teaching portfolio (Berk, 2005). In instances where teaching effectiveness was evaluated by sources other than students such as alumni, faculty colleagues, and classroom teaching experts, the ratings were consistent with those of the students (Murray, 1983). However, the research findings affirm the crucial role of student ratings, as sufficient support for other indicators' validity could not be gathered (Marsh and Roche, 1997).

Teaching effectiveness has been attributed to many factors, which usually include teacher personality factors, environmental factors, courserelated factors, and system-related factors. Blattner and Baldwin (2003) inferred that the personal characteristics of the teacher were reported to be the most prominent factor (67\%) in teacher evaluation as perceived by the students, followed by the teachers' knowledge of the subject (57\%), and preparedness of the teacher to conduct the class (53\%). Some other studies have pointed out teacher preparedness to be highly significant (Darling Hammond et al., 2002; Darling-Hammond et al., 2005; Harper et al., 1990). Another essential aspect includes the pedagogy used in the classroom, which determines actual learning and student rating (Ball, 2000). Roberts and Dyer (2004) also found that the way content is delivered, the instruction methods followed in the classroom impact the student ratings of teaching effectiveness. Thus, pedagogy also depicts the classroom behavior of the teacher. The pedagogical factor is further substantiated by the findings of Murray (1983). He states that teachers vary on exhibiting lowinference teaching behaviors, among which enthusiasm, subject clarity, and rapport with students are significantly related to teaching quality (Murray, 1983). Those teachers higher on these three aspects are supposedly higher on student ratings also. Therefore, Murray (1983) concludes that student rating is impacted more by classroom behaviors than external factors such as teacher personality or popularity.

Further, teacher attitude towards students is also taken up by previous studies in various forms. For enhancing the attention span of the student, expressive behavior serves better. It communicates the teacher's enthusiasm and simultaneously impacts other critical teaching behaviors as well, which overall affect teaching quality (Murray, 1983). Another aspect of the teacher-student relationship includes teacher immediacy. Teacher immediacy indicates those communication behaviors that increase the understanding and non-verbal interaction between the teacher and the student (Anderson, 1979). It is considered a strong predictor of teaching effectiveness. It also provides insight into the formulation of student perception towards a teacher (Anderson, 1979).

\section{METHODOLOGY}

The study assesses the teaching effectiveness of teachers in the various social sciences disciplines. Teachers' characteristics and qualities, which are seen by students as their teaching strengths, are essential to understand. In contrast, the sections of personality characteristics and teachers' pedagogical approaches are equally important to identify when students are not happy. Thus, to evaluate the teachers' characteristics, their impact on students' learning, and overall teaching effectiveness following research questions of the study were designed.

- What are the various categories of teachers based on the multiple attributes of teachers obtained via student ratings?

- Are teachers' attributes correlated with the overall efficacy of teaching? 
- Can we create an Efficiency System of Teaching based on instructor attributes closely linked to teaching effectiveness?

\section{Sampling}

The study is focused on assessing the teaching quality of university teachers in social sciences. Therefore, all the graduating students of the department of economics and education of Lahore College for Women University (LCWU) registered for the BS Education and Economics. They were taken as respondents. The sample size was $300(n=300)$. A scientifically developed and pre-tested questionnaire was administered for the study. The students completed the semester with 48 credit loads and took regular classes with different teachers in registered courses. All the courses registered during the semester and all the teachers teaching during the semester were brought under the study. The teachers were from the Department of Economics, Education, Business, and Humanities.

\section{Variables}

Based on the literature review and focused grouped discussion, eight attributes (seven teacher attributes and one attribute related to the course being taught) were identified for inclusion in the student evaluation questionnaire. It included teacher preparedness, teaching pedagogy, of course, teacher's attitude towards students, teacher's attitude towards teaching, teacher's creativity, teacher's fairness, teacher's availability to students, and course characteristics. A selfmanaged questionnaire was designed to determine whether the students agree or disagree with these teacher's attributes. The instrument was rated on a five-point ordinal scale, ranging from 1(strongly disagree) to 5 (strongly agree).
Table 1 shows different items under teacher's attributes and course characteristics. Teacher preparedness consists of 5 items (item 1-5) with the maximum attainable score of 300 and minimum achievable score of 60 , teaching pedagogy of course consists of 6 items (item 6-11) with the maximum possible score of 360 and minimum attainable score of 72 , teacher's attitude towards students consists of 4 items (item 12-15) with the maximum achievable score of 240 and minimum possible score of 36 , teacher's attitude towards teaching consists of 2 items (article 16 and 17) with the maximum attainable score of 120 and minimum achievable score of 24, teacher's creativity consists of 3 items (item 18-20) with the maximum possible score of 180 and minimum attainable score of 36 , teacher's fairness consists of 2 items (item 21 and 22) with the maximum achievable score of 120 and minimum possible score of 24 , teacher's availability to students consists of 3 items (item 23-25) with the maximum attainable score of 180 and minimum achievable score of 36 , and finally course characteristics consists of 5 items (item 26-30) with the maximum possible score of 300 and minimum attainable score of 60 . The dependent variable overall teaching effectiveness was measured using the last three items (item 31-33), and the items measured on a 5-point Likert response format with anchors from 1 (strongly disagree) to 5 (strongly agree).

Teachers were categorized under high, medium, and low based on the mean and standard deviation of scores obtained by totaling item scores under each attribute. Table 1 shows teachers' categorization criteria as high, medium, and low based on student rating on selected characteristics. 
Table 1: Values for Categorization of Teachers as High, Medium and Low based on Student Rating on Selected Attributes

\begin{tabular}{|c|l|c|c|}
\hline S. No. & \multicolumn{1}{|c|}{ Attributes } & $\begin{array}{c}\text { High [Greater than } \\
\text { (Mean +S. D.)] }\end{array}$ & $\begin{array}{c}\text { Low [Smaller than } \\
\text { (Mean -S. D.)] }\end{array}$ \\
\hline 1. & Teacher Preparedness & 233.82 & 151.77 \\
\hline 2. & Teaching Pedagogy Of Course & 254.55 & 152.03 \\
\hline 3. & Teachers Attitude Towards Students & 177.93 & 110.21 \\
\hline 4. & Teachers Attitude Towards Teaching & 90.18 & 54.44 \\
\hline 5. & Teachers Creativity & 128.53 & 78.01 \\
\hline 6. & Teachers Fairness & 108.89 & 34.65 \\
\hline 7. & Teachers Availability To Students & 127.81 & 74.49 \\
\hline 8. & Course Characteristics & 214.35 & 135.83 \\
\hline
\end{tabular}

(Medium category values lie between (Mean + S. D.) and (Mean - S. D.)

The data collected were analyzed using the $\mathrm{R}$ program. The descriptive analysis used frequency and percentage for the categorization of teachers based on various attributes. Three types of data analysis were used: Pearson Moment Correlation, ANOVA, and multiple hierarchical regressions to find associations of items and teachers' characteristics with overall teaching effectiveness and test the significance. The significance level was determined at probability levels of $1 \%$ and $5 \%$.

\section{FINDINGS}

It is evident from Table 2 that among all the attributes, four attributes, namely teacher preparedness, teacher's fairness, teaching pedagogy of course, and course characteristics, were ranked highest by students under the high category. $40.96 \%$ of students rated teacher preparedness of teachers under the high sort followed by teacher's fairness $(32.58 \%)$, teaching pedagogy of course (31.29\%), and course characteristics $(30.32 \%)$. Among these four attributes, $60.98 \%$ of students rated course characteristics under the medium category, followed by teacher's fairness $(57.10 \%)$, teaching pedagogy of course (53.23\%), and teacher's preparedness $(47.75 \%)$. Also, the percentage of students rating these four attributes under the low category was considerably less with teaching pedagogy of course at $15.48 \%$, followed by teacher preparedness $(11.29 \%)$, teacher fairness $(10.32 \%)$, and course characteristics $(08.70 \%)$.
Thus, the majority of students rated these four attributes under high and medium category when summed together; teacher preparedness $(88.70 \%)$, teacher's fairness $(89.68 \%)$, teaching pedagogy of course $(84.52 \%)$, and course characteristics (91.30 $\%$ ), and significantly lower number of students rated these attributes under the low category. It indicates that the majority of teachers prepare lecture schedules, regularly checkup class attendance, arrive on time and leave on time, completes the entire course content, demonstrate a good knowledge of the subject, utilize the knowledge gained through wide reading, deliver the subject matter virtually, provide additional material, make efficient use of multi-media tools, and depict fairness in grading. It also signifies that most students believe that the given course integrates theoretical concepts with practical applications, assignments, and examinations covering the course materials. Course material is relevant and updated, and the credit hour allotted to the course is sufficient.

Table 2 also suggests that a lower number of students ranked the remaining four attributes (teacher's attitude towards students, teacher's attitude towards teaching, teacher's creativity, and teacher's availability to students) under the high category, and a noticeably higher number of students ranked them under the low category. The values for each of them depict so, teacher's attitude towards students' (16.78\% and 20.96\%), teacher's availability to students $(16.12 \%$ and 
$15.80 \%)$, teachers' creativity $(15.48 \%$ and $32.58 \%$ ), and teachers' attitude towards teaching (14.19\% and 22.90 Percent). It implies that the students think that teacher responsiveness to students, teachers' sensitivity, attention and respect for students, the teacher's enthusiasm, the teacher's receptivity to new ideas, teacher's capacity to guide debate, and teacher access to classrooms are relatively lower. Overall, the majority $(>50 \%)$ of students rated all attributes under the medium category, with $44.83 \%$ and $40.33 \%$ of students rating overall teaching effectiveness under high and medium sort, respectively, with $14.84 \%$ low category.

Table 2: Distribution of the Teachers as High, Medium and Low based on Student Ratings on Selected Attributes Using Frequency and Percentage Basis

\begin{tabular}{|c|l|c|c|c|c|c|c|}
\hline \multirow{2}{*}{ Attributes } & \multicolumn{2}{c|}{ Hig 1 } & \multicolumn{2}{c|}{ Medium } & \multicolumn{3}{c|}{ Low } \\
\cline { 3 - 8 } & & Frequency & $\%$ & Frequency & $\%$ & Frequency & $\%$ \\
\hline 1. No. & Teacher Preparedness & 127 & 40.96 & 148 & 47.75 & 35 & 11.29 \\
\hline 2. & Teaching Pedagogy of Course & 97 & 31.29 & 165 & 53.23 & 48 & 15.48 \\
\hline 3. & Teachers Attitude Towards Students & 52 & 16.78 & 193 & 62.26 & 65 & 20.96 \\
\hline 4. & Teachers Attitude Towards Teaching & 44 & 14.19 & 195 & 62.91 & 71 & 22.90 \\
\hline 5. & Teachers Creativity & 48 & 15.48 & 161 & 51.94 & 101 & 32.58 \\
\hline 6. & Teachers Fairness & 101 & 32.58 & 177 & 57.10 & 32 & 10.32 \\
\hline 7. & Teachers Availability to Students & 50 & 16.12 & 211 & 68.08 & 49 & 15.80 \\
\hline 8. & Course Characteristics & 94 & 30.32 & 189 & 60.98 & 27 & 08.70 \\
\hline 9. & Overall teaching effectiveness & 139 & 44.83 & 125 & 40.33 & 46 & 14.84 \\
\hline
\end{tabular}

Pearson correlations were computed between all attributes and overall teaching effectiveness to test for the correlation's direction and strength. All attributes were found to be positively correlated with overall teaching effectiveness. Table 3 shows Pearson correlation coefficients between all attributes and overall teaching effectiveness. Multiple regression analysis indicates that two attributes, teacher preparedness and course characteristics, were significantly associated with overall teaching effectiveness at $0.01 \%$ level. While six other attributes, namely teaching pedagogy, teacher's attitude towards students, teacher's attitude towards teaching, teacher's creativity, teacher's fairness, and teacher's availability to students were significantly linked with overall teaching effectiveness $0.05 \%$ level. Thus, it can be concluded that all attributes are associated considerably with comprehensive teaching effectiveness Table 3).

Table 3: Association between Various Attributes and Overall Teaching Effectiveness $(\mathbf{n}=\mathbf{3 1 0})$

\begin{tabular}{|c|l|c|c|c|c|}
\hline S. No. & \multicolumn{1}{|c|}{ Attributes } & Mean & S. D. & $\begin{array}{c}\text { Pearson Correlation } \\
\text { Coefficient (r) }\end{array}$ & p Value \\
\hline 1. & Teacher Preparedness & 192.80 & 41.02 & 0.20711 & $0.0046^{* *}$ \\
\hline 2. & Teaching Pedagogy Of Course & 203.28 & 51.27 & 0.13776 & $0.0285^{*}$ \\
\hline 3. & Teachers Attitude Towards Students & 144.07 & 33.86 & 0.16748 & $0.0243^{*}$ \\
\hline 4. & Teachers Attitude Towards Teaching & 72.31 & 17.87 & 0.13130 & $0.0384^{*}$ \\
\hline 5. & Teachers Creativity & 103.27 & 25.26 & 0.17738 & $0.0221^{*}$ \\
\hline 6. & Teachers Fairness & 71.77 & 37.12 & 0.13729 & $0.0483^{*}$ \\
\hline 7. & Teachers Availability To Students & 101.15 & 26.66 & 0.14397 & $0.0337^{*}$ \\
\hline 8. & Course Characteristics & 175.09 & 39.26 & 0.16305 & $0.0035^{* *}$ \\
\hline
\end{tabular}

$* *$ significant at $0.01 \%$ level, *significant at $0.05 \%$ level 


\section{DISCUSSIONS}

The findings of the study are consistent with previous research, especially in the case of support for teacher preparedness (DarlingHammond et al., 2002; Darling-Hammond et al.,2005; Harper et al.,1990), teaching pedagogy of course (Ball, 2000; Roberts and Dyer, 2004), teacher's attitude towards students, and teacher's attitude towards teaching (Blattner and Baldwin, 2003; Murray, 1983; Murray, 1987). Some attributes have not mainly been empirically examined in previous studies, such as teachers' creativity, teacher's fairness, teacher's availability to students, and course characteristics. Therefore, this study contributes to providing empirical evidence for these attributes within the agricultural education setting.

Studies have revealed that the students who spend the semester with the course and observe the teachers. Throughout the semester, it will efficiently evaluate the course content and overall teaching performance (Thealland Franklin, 2001). Thus, based on the above findings, a teaching effectiveness framework is designed. For developing the framework, each item under all attributes was checked for significant association with overall teaching effectiveness. Table 4 represents all items under various features and their association with overall teaching effectiveness. "The teacher is always well prepared for each class" (item 4), "the syllabus clearly states course objectives, requirements, procedures and grading criteria" (item 26), and "the assignments and exams cover the materials presented in course" (item 28) were significantly associated with "overall teaching effectiveness" at $0.01 \%$ level. 'The teacher provides additional material apart from the textbook' (item 9), 'the teacher give citations regarding the current situation concerning Indian context' (item 10), 'the teacher organizes remedial teaching to overcome students weakness' (item 24), 'the teacher extends full cooperation in co-curricular activities and make a constructive contribution for further improvement' (item 25), and 'the credit hour allotted to the course is sufficient' (item 30) were not significantly associated with overall teaching effectiveness, and thus dropped from teaching effectiveness framework, while rest of the items were significantly associated with 'overall teaching effectiveness' at $0.01 \%$ level and included in teaching effectiveness framework.

Table 4: Items under Various Attributes and their Association between Overall Teaching Effectiveness $(n=300)$

\begin{tabular}{|l|l|l|l|l|}
\hline S. No. & Item & Mean & S. D. & p value \\
\hline 1. & $\begin{array}{l}\text { The teacher prepares a lecture schedule for students at the } \\
\text { beginning of the semester }\end{array}$ & 37.23 & 9.47 & $0.0236^{*}$ \\
\hline 2. & The teacher regularly checks ups class attendance & 40.26 & 7.35 & $0.0145^{*}$ \\
\hline 3. & The teacher arrives on time and leaves on time & 39.61 & 8.47 & $0.0456^{*}$ \\
\hline 4. & The teacher is always well prepared for each class & 38.45 & 7.13 & $0.0013^{* *}$ \\
\hline 5. & The teacher completes the whole course & 37.59 & 6.69 & $0.0469^{*}$ \\
\hline 6. & The teacher demonstrates good knowledge of subject & 41.25 & 4.59 & $0.0321^{*}$ \\
\hline 7. & $\begin{array}{l}\text { The teacher utilizes the knowledge gained through wide reading to } \\
\text { increase the effectiveness in teaching }\end{array}$ & 32.89 & 8.11 & $0.0113^{*}$ \\
\hline 8. & $\begin{array}{l}\text { The teacher delivers the subject matter effectively with clarity and } \\
\text { coherence }\end{array}$ & 39.12 & 6.91 & $0.0472^{*}$ \\
\hline 9. & The teacher provides additional material apart from textbook & 27.07 & 12.13 & 0.0891 \\
\hline 10. & The teacher gives citations regarding current situation with & 29.15 & 13.27 & 0.0751 \\
\hline
\end{tabular}




\begin{tabular}{|c|c|c|c|c|}
\hline & reference to Indian context & & & \\
\hline 11. & $\begin{array}{l}\text { The teacher makes the best use of multi-media tools for effective } \\
\text { teaching }\end{array}$ & 36.67 & 7.77 & $0.0116 *$ \\
\hline 12. & The teacher is responsive to students' questions & 38.44 & 7.13 & $0.0231 *$ \\
\hline 13. & The teacher is sensitive to students' problems & 30.03 & 5.91 & $0.0678 *$ \\
\hline 14. & $\begin{array}{l}\text { The teacher shows respect towards students and encourages class } \\
\text { participation }\end{array}$ & 32.11 & 8.89 & $0.0237 *$ \\
\hline 15. & $\begin{array}{l}\text { Teachers pays attention to all students irrespective of their abilities } \\
\text { or personal characteristics }\end{array}$ & 34.81 & 7.97 & $0.0342 *$ \\
\hline 16. & The teacher has high enthusiasm & 31.27 & 10.11 & $0.0211 *$ \\
\hline 17. & $\begin{array}{l}\text { The teacher regards teaching as a noble profession and has } \\
\text { cultivated and imbibed a code of conduct, vocabulary and a } \\
\text { disposition worthy of a noble profession }\end{array}$ & 35.55 & 8.76 & $0.0376 *$ \\
\hline 18. & The teacher is receptive to new ideas and disagreement & 28.67 & 13.11 & $0.0413 *$ \\
\hline 19. & The teacher is able in directing discussion & 36.52 & 10.04 & $0.0399 *$ \\
\hline 20. & $\begin{array}{l}\text { The teacher identifies the weakness and strengths of students and } \\
\text { uses them for future planning }\end{array}$ & 28.77 & 9.97 & $0.0412 *$ \\
\hline 21. & The teacher is fair in grading & 41.56 & 5.76 & $0.0431 *$ \\
\hline 22. & $\begin{array}{l}\text { The teacher returns and shows the graded scripts in a reasonable } \\
\text { amount of time }\end{array}$ & 35.70 & 3.77 & $0.0124 *$ \\
\hline 23. & $\begin{array}{l}\text { The teacher is available during specified official hours and for } \\
\text { after class consultations }\end{array}$ & 27.17 & 7.45 & $0.0316^{*}$ \\
\hline 24. & $\begin{array}{l}\text { The teacher organizes remedial teaching to overcome student's } \\
\text { weakness }\end{array}$ & 30.84 & 13.67 & 0.0975 \\
\hline 25. & $\begin{array}{l}\text { The teacher extends full cooperation in co-curricular activities and } \\
\text { makes a constructive contribution for further improvement }\end{array}$ & 27.66 & 6.67 & 0.6721 \\
\hline 26. & $\begin{array}{l}\text { The syllabus clearly states course objectives, requirements, } \\
\text { procedures and grading criteria }\end{array}$ & 41.23 & 5.55 & $0.0012 * * \mid$ \\
\hline 27. & $\begin{array}{l}\text { The course integrates theoretical course concepts with real world } \\
\text { applications }\end{array}$ & 38.53 & 5.43 & $0.0369 *$ \\
\hline 28. & $\begin{array}{l}\text { The assignments and exams cover the materials presented in } \\
\text { course }\end{array}$ & 44.61 & 4.89 & $0.0023 * *$ \\
\hline 29. & The course material is modern and updated & 25.34 & 6.99 & $0.0475^{*}$ \\
\hline 30. & The credit hour allotted to the course are sufficient & 37.50 & 4.01 & 0.8122 \\
\hline 31. & $\begin{array}{l}\text { The subject matter presented in the course has increased your } \\
\text { knowledge of the subject }\end{array}$ & 40.03 & 10.33 & \\
\hline 32. & Overall, the teaching of the course is effective & 36.54 & 7.80 & - \\
\hline 33. & $\begin{array}{l}\text { Overall, the teacher is one of the best and have essential teaching } \\
\text { skills }\end{array}$ & 31.39 & 6.54 & - \\
\hline
\end{tabular}




\section{CONCLUSIONS}

Due to the number of universities experiencing difficulty achieving academic excellence and witnessing low teaching effectiveness, it is becoming increasingly important to determine what attributes of a teacher affect overall teaching effectiveness. To better understand this question, teachers' details were examined, and teachers were categorized along with the association of those attributes with overall teaching effectiveness. It was found that teachers were performing better in four attributes, namely teacher preparedness, teacher's fairness, teaching pedagogy of course, and course characteristics as compared to another four attributes, namely teacher's attitude towards students, teacher's attitude towards teaching, teacher's creativity, and teacher's availability to students. Specifically, it was revealed that all attributes were positively correlated with overall teaching effectiveness with two attributes, teacher preparedness and course characteristics, which were found highly significant (associated with overall teaching effectiveness at $0.01 \%$ level).

Based on the conclusions from this study, some recommendations were formulated for teachers and teacher training institutions. However, these suggestions are not restricted to teachers and teacher training institutions in Pakistan since this study's conclusions concur with other studies concerning teachers' teaching attributes. This study's results can also be useful for policymakers around the world, who are addressing the issues of recruitment and retention of teachers, structuring their works, improving the teacher training system, and developing the effectiveness of teaching. In summary, the most important recommendations of this study are listed below:

- Teachers should consider all teacher's attributes and attempt to increase their performance in those attributes, where students have perceived them comparatively low.

- Teachers can consider the teaching effectiveness framework developed from the present study's outcomes and use it as cross-reference for their overall preparation. Teaching effectiveness can be further enhanced.

- Teacher training institutions should concentrate on teacher's attributes revealed by this study and try to develop teachers' capacity in these attributes.

- Authorities in universities should include these attributes in their teacher's evaluation process and generate relevant data to further investigate and improve the teacher's evaluation process.

This study aimed to investigate teachers' attributes of teachers in LCWU to find the association of teacher's attributes with overall teaching effectiveness and frame a teaching effectiveness framework. Accordingly, we tried to make a useful contribution to the teacher education literature. Although many studies have been carried out on teaching effectiveness and factors affecting it, this study can contribute to the field in three ways. Firstly, it will help existing teachers assess themselves with the help of teachers' attributes generated by this study. Secondly, teachers can cross-check their teaching preparation by comparing their strategy with the teaching effectiveness framework. Third, authorities can utilize the present finding and teaching effectiveness framework in their teacher's evaluation process.

\section{REFERENCES}

[1] Andersen, J. F. (1979). Teacher immediacy as a predictor of teaching effectiveness. Annals of the International Communication Association, 3(1), 543-559.

[2] Ball, D. L. (2000). Bridging practices: Intertwining content and pedagogy in teaching and learning to teach. Journal of Teacher Education, 51(3), 241-247.

[3] Berk, R. A. (2005). Survey of 12 strategies to measure teaching effectiveness. International Journal of Teaching and Learning in Higher Education, 17(1), 48-62. 
[4] Berk, R. A. (2013). Top five flashpoints in the assessment of teaching effectiveness. Medical Teacher, 35(1), 15-26.

[5] Baldwin, T., \& Blattner, N. (2003). Guarding against potential bias in student evaluations: What every faculty member needs to know. College Teaching, 51(1), 27-32.

[6] Cano, J., Garton, B. L., \& Raven, M. R. (1992). Learning styles, teaching styles and personality styles of preservice teachers of agricultural education. Journal of Agricultural Education, 33(1), 46-52.

[7] Chen, Y., \& Hoshower, L. B. (2003). Student evaluation of teaching effectiveness: An assessment of student perception and motivation. Assessment \& Evaluation in Higher Education, 28(1), 71-88.

[8] Darling-Hammond, L., Chung, R., \& Frelow, F. (2002). Variation in teacher preparation: How well do different pathways prepare teachers to teach? Journal of Teacher Education, 53(4), 286-302.

[9] Darling-Hammond, L., Holtzman, D. J., Gatlin, S. J., \& Vasquez Heilig, J. (2005). Does teacher preparation matter? Evidence about teacher certification, Teach for America, and teacher effectiveness. Education Policy Analysis Archives, 13(42). http://epaa.asu.edu/epaa/v13n42/. Accessed on June 20, 2018.

[10] Food and Agriculture Organization (2014). Youth and agriculture: Key challenges and concrete solutions. http://www.fao.org/3/ai3947e.pdf. Accessed June 20, 2018.

[11] Galbraith, C. S., Merrill, G. B., \& Kline, D. M. (2012). Are student evaluations of teaching effectiveness valid for measuring student learning outcomes in business related classes? A neural network and Bayesian analyses. Research in Higher Education, 53(3), 353-374.

[12] Harper, J. G., Weiser, R. G., \& Armstrong, R. F. (1990). Factors associated with western region agriculture teachers' perceptions of teaching effectiveness. Journal of Agricultural Education, 31(4), 22-26.

[13] Archana, S., \& Usha Rani, K. (2017). Role of a Teacher in English Language Teaching (ELT). International Journal of Educational Science and Research (IJESR), 7(1), 1-4.

[14] Lin, R., Xie, J., Jeng, Y. C., \& Huang, S. (2010). The relationship between teacher quality and teaching effectiveness perceived by students from industrial vocational high schools. Asian Journal of Arts and Sciences, 1(2), 167-187.

[15] Marsh, H. W., \& Bailey, M. (1993). Multidimensional students' evaluations of teaching effectiveness: A profile analysis. The Journal of Higher Education, 64(1), 1-18.

[16] Marsh, H. W., \& Roche, L. (1993). The use of students' evaluations and an individually structured intervention to enhance university teaching effectiveness. American Educational Research Journal, 30(1), 217-251.

[17] Marsh, H. W., \& Roche, L. A. (1997). Making students' evaluations of teaching effectiveness effective: The critical issues of validity, bias, and utility. American Psychologist, 52(11), 1187-1197.

[18] McKim, A. J., \& Velez, J. J. (2015). Exploring the Relationship between SelfEfficacy and Career Commitment among Early Career Agriculture Teachers. Journal of Agricultural Education, 56(1), 127-140.

[19] Murray, H. G. (1983). Low-inference classroom teaching behaviors and student ratings of college teaching effectiveness. Journal of Educational Psychology, 75(1), 138-149.

[20] Roberts, T. G., \& Dyer, J. E. (2004). Characteristics of effective agriculture teachers. Journal of Agricultural Education, 45(1), 82-95.

[21] Rockoff, J. E., \& Speroni, C. (2010). Subjective and objective evaluations of teacher effectiveness. American Economic Review, 100(2), 261-66. 
[22] Seidel, T., \& Shavelson, R. J. (2007). Teaching effectiveness research in the past decade: The role of theory and research design in disentangling meta-analysis results. Review of Educational Research, 77(4), 454499.

[23] Stronge, J. H., Ward, T. J., \& Grant, L. W. (2011). What makes good teachers good? A cross-case analysis of the connection between teacher effectiveness and student achievement. Journal of Teacher Education, 62(4), 339-355.

[24] Theall, M. \& Franklin, J., (2001). Looking for the bias in all the wrong places: A search for truth or a witch hunt in student rating of instructions? New Direction for Institutional Research, 109, 45-56 